\title{
Association between the polymorphism of IL-17A and IL-17F gene with knee osteoarthritis risk: a meta-analysis based on case-control studies
}

\author{
Feifan Lu' ${ }^{1}$ Pei Liu², Qidong Zhang ${ }^{3 *}$, Weiguo Wang ${ }^{3}$ and Wanshou Guo ${ }^{3}$
}

\begin{abstract}
Background: Knee osteoarthritis is a joint disease which is characterized by degeneration of articular cartilage and subsequent subchondral bone changes. Polymorphisms of IL-17A/F gene were the recognized candidate genes associated with knee osteoarthritis risk although the results were conflicting. The aim of this study was to determine whether IL-17A(rs2275913) and IL-17F(rs763780) polymorphisms confer susceptibility to knee osteoarthritis.

Method: Literature search was performed in PubMed, Medline, Cochrane Library, Web of science, Embase, and Google Scholar (last search was updated on June 20, 2019), and assessing this association was performed by calculating odds ratios with $95 \%$ confidence intervals. Statistical heterogeneity was quantitatively evaluated by using the $Q$ statistic with its $p$ value and $P^{2}$ statistic.

Result: Six case-control based studies were included involving IL-17A(rs2275913) (2134 cases and 2306 controls) and IL-17F(rs763780) (2134 cases and 2426 controls). The overall analysis suggested that the A allele of the rs 2275913 polymorphism, and the $\mathrm{C}$ allele of the rs 763780 polymorphism in the IL-17 gene may increase the risk of OA. However, subgroup analysis revealed that no association between IL-17A(rs2275913) gene and knee OA risk was found in Caucasian population.

Conclusions: This meta-analysis revealed that the IL-17A(rs2275913) gene polymorphisms may increase the risk of knee OA in Asians, and the IL-17F(rs763780) gene polymorphisms may increase the risk of knee OA both in Asians and Caucasians. However, because of the limitations of the present study, additional larger studies are needed to confirm our findings in the future.
\end{abstract}

Keywords: IL-17, Polymorphisms, Knee, Osteoarthritis, Meta-analysis

\section{Background}

Knee osteoarthritis (OA) is a common joint disease which is characterized by degeneration of articular cartilage and subsequent subchondral bone changes [1]. The incidence of knee OA is high, with an estimated 14 million symptomatic patients in the USA [2]. Therefore, it is an enormous burden on the national economy and healthcare system. Knee OA is a combined consequence

\footnotetext{
* Correspondence: zhangqidong1982@pku.edu.cn

${ }^{3}$ Department of Orthopedic Surgery, Beijing Key Lab Immune-Mediated Inflammatory Diseases, China-Japan Friendship Hospital, No.2 Yinghua East Street, Beijing ,100029, China

Full list of author information is available at the end of the article
}

of environmental and genetic factors, while genetic factors account for nearly $50 \%$ of the risk of knee OA development [3]. Though the underlying mechanisms remain unknown, many studies have demonstrated that the occurrence of osteoarthritis is related to genetic factors, including interleukin-17 family [4-7].

Interleukin-17 (IL-17) families include six members (A, $\mathrm{B}, \mathrm{C}, \mathrm{D}, \mathrm{E}, \mathrm{F})$, and they play active roles in autoimmune diseases and inflammatory diseases $[8,9]$. IL-17A is a member of IL-17 families and is a pro-inflammatory cytokine associated with many inflammatory diseases, such as rheumatoid arthritis (RA), ankylosing spondylitis, and systemic lupus erythematosus [10]. Similarly, IL-17F earned

(C) The Author(s). 2019 Open Access This article is distributed under the terms of the Creative Commons Attribution 4.0 International License (http://creativecommons.org/licenses/by/4.0/), which permits unrestricted use, distribution, and 
increasing attention due to its great comparability of IL17A. Previous studies reveal that IL-17 is expressed in synovial tissues, and could contribute to cartilage degeneration, the main cause of knee OA, by inducing the release of chemokines by chondrocytes [11]. Although knee OA is considered a non-inflammatory condition earlier, with further researches on its physiopathology, it is generally believed that immune cell infiltration and cytokine secretion are a feature of knee OA [12]. The expression of IL17A and IL-17F has turned out to be affected by single nucleotide polymorphisms (SNPs). These polymorphisms have allele-specific effects on the regulation of IL-17 gene transcription and are associated with the development and/or progression of some common diseases [13]. Thus, we hypothesized that IL-17A(rs2275913) and IL$17 \mathrm{~F}(\mathrm{rs} 763780)$ gene polymorphisms are associated with knee OA risk.

Up to now, several studies have investigated the relationships of IL-17A(rs2275913) and IL-17F(rs763780) polymorphism with knee OA risk in different countries and draw different conclusions [14-19]. Jiang [14] and Han [15] found that the IL-17A(rs2275913) polymorphism was involved in high risk of KOA while the IL17F(rs763780) was not. Bai [16] and Eftedal [19] found that IL-17A/F gene polymorphisms all related to the high-risk knee OA occurrence. Bafrani [18] found that IL-17A(rs2275913) gene may be a protective factor against knee osteoarthritis while the IL-17F(rs763780) gene may be a risk factor for knee osteoarthritis. Vrgoc [17] revealed that neither IL-17A nor IL-17F were related to the knee OA. Therefore, we conducted a metaanalysis to overcome the limitations of individual studies and to search for relevance in their findings. The purpose of this study was to evaluate whether the IL17A(rs2275913) and IL-17F(rs763780) polymorphisms are associated with the risk of knee OA.

\section{Materials and methods}

\section{Literature search strategy}

We conducted a comprehensive literature search using the electronic databases PubMed, Medline, Cochrane Library, Web of science, Embase, and Google Scholar to identify studies published in English (last search was updated on June 20,2019). The search strategy was based on the following keywords: ("IL-17" OR "interleukin-17") OR ("polymorphism" OR "variant" OR "SNP") AND ("knee osteoarthritis" OR "KOA"). No other restrictions were placed on the search. Full text was obtained if the abstract was insufficient to allow us to include or exclude a study. Furthermore, the reference lists of all the related citations were examined to identify any initially omitted studies. All the literature searches were performed according to the Preferred Reporting Items for Systematic Reviews and Meta-Analyses (PRISMA) guidelines (Additional file 1).
According to the following criteria, six studies were included in this meta-analysis (Fig. 1).

\section{Inclusion and exclusion criteria}

Two researchers screened the relevant investigations and further determined the eligible studies which met the following inclusion criteria: (1) case-control study on humans, (2) study evaluating the association between IL$17 \mathrm{~A}(\mathrm{rs} 2275913)$ and IL-17F(rs763780) gene polymorphisms and susceptibility to knee OA, and (3) study with sufficient genetic frequency for extraction. The exclusion criteria were as follows: (1) insufficient data on genotype or allele frequency for calculation of odds ratio (OR) and corresponding 95\% confidence interval (CI); (2) animal model research, review or case report; and (3) duplicate or overlapping publication. In cases of uncertainty regarding any of the above essential information, all questionable publications were discussed and addressed by consensus. The full article was retrieved for further scrutiny, or the authors of the individual trials were contacted directly for further information when necessary.

\section{Data extraction}

Two researchers extracted all data independently according to the criteria described above. We developed a data extraction sheet including year of publication, the first author's name, ethnicity, source of control groups, genotype, genotyping method, and allele frequency. Any controversies of the data were discussed within our research team and the authors reached a consensus on all items.

\section{Study quality assessment}

Study quality assessment was conducted by using the Newcastle-Ottawa Quality Assessment Scale (NOS). The quality score of each study was based on three categories: selection ( 4 items, 1 point each), comparability (1 item, up to 2 points), and exposure/outcome (3 items, 1 point each). Each study scored from 0 point (worst) to 9 points (best), and scored 6 or less were classified as low quality, whereas studies scoring 7 or higher were defined as high quality. The results of study quality assessment were shown in Tables 1 and 2.

\section{Statistical analysis}

Pooled odds ratios (ORs) with 95\% confidence intervals (CIs) were calculated to assess the association between IL17A(rs2275913) and IL-17F(rs763780) gene polymorphisms and knee OA susceptibility. The observed genotype frequencies in control groups of the IL-17A(rs2275913) and IL17F(rs763780) gene polymorphisms were assessed for Hardy Weinberg equilibrium (HWE) by using the Chi-square test. Three genetic models were used: (1) allele model, (2) recessive model, and (3) dominant model. $p<0.05$ was considered 


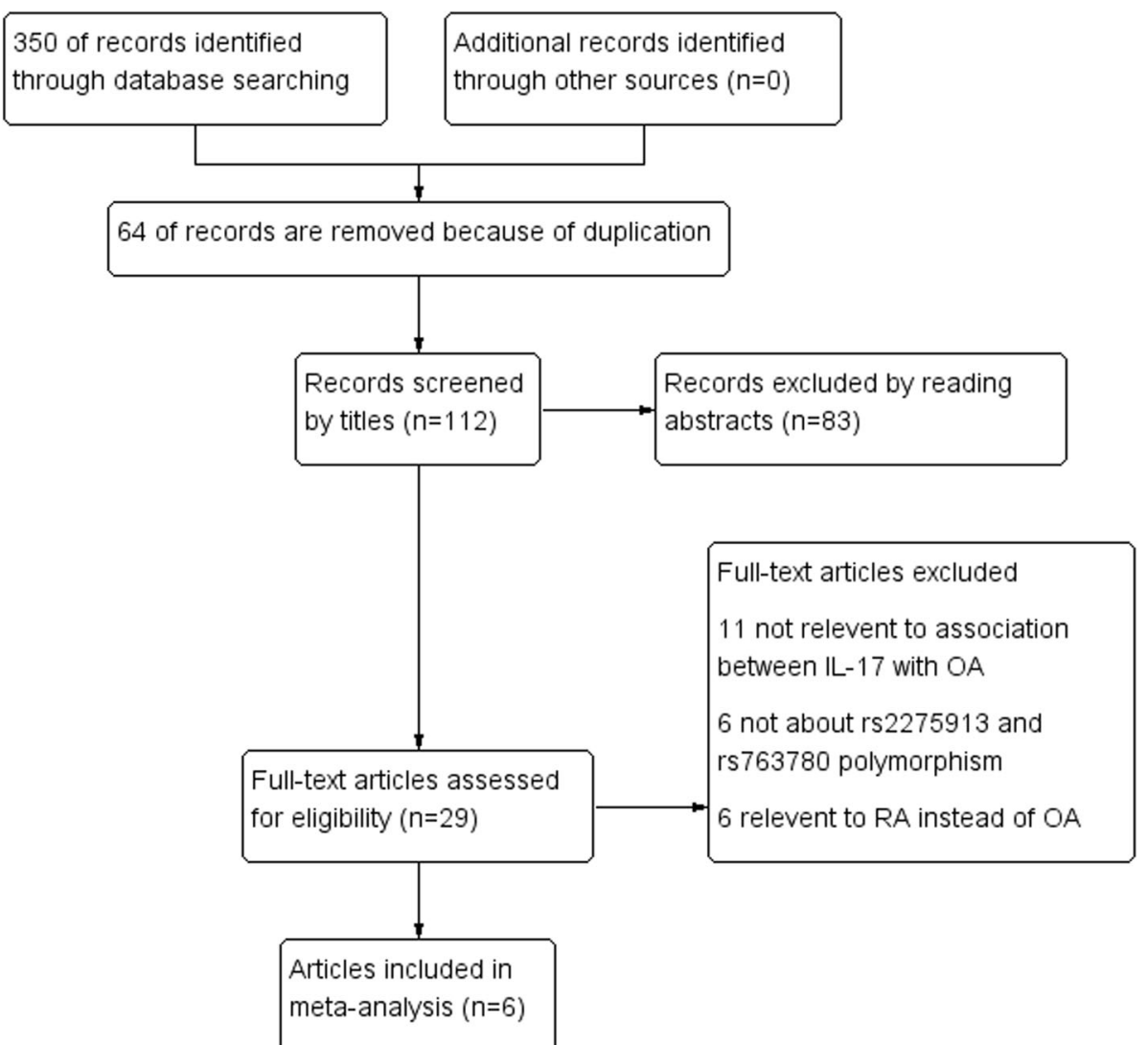

Fig. 1 Flowchart of the literature search and selection for the present study

significant. Heterogeneity assumption across studies were assessed by using the $Q$ statistic with its $p$ value and $I^{2}$ statistic. If $I^{2}<50 \%$ and $p>0.10$, a fixed effects model was used in the calculations, otherwise, a random effects model was applied [20, 21]. Subgroup analysis was carried out on the basis of ethnicity. Potential publication bias was assessed with Begg's test. Sensitivity analysis by omitting each study in turn determines the impact on the heterogeneity test and assessing the stability of the overall results. All statistical analyses were conducted in Stata15.1 (Stata Corporation, College Station, TX, USA).

\section{Results}

Characteristics of the included studies

The online search yielded 350 records, of which $64 \mathrm{du}-$ plicates were removed. Then 83 of 112 remaining records were excluded after reviewing of abstracts. The remaining 29 articles were sent for full text review, which excluded 11 articles without relevant to the association between IL-17 gene with knee OA, 6 not about rs2275913 and rs763780 polymorphism, and 6 relevant to RA instead of knee OA (Fig. 1). Finally, we identified six case-control studies about the association between

Table 1 Characteristics of the included studies of IL-17A(rs2275913)

\begin{tabular}{|c|c|c|c|c|c|c|c|c|c|c|c|c|}
\hline \multirow[t]{2}{*}{ Authors } & \multirow[t]{2}{*}{ Years } & \multicolumn{3}{|c|}{ Case } & \multicolumn{3}{|c|}{ Control } & \multirow[t]{2}{*}{ Genotype } & \multirow{2}{*}{$\begin{array}{l}\text { Genotyping } \\
\text { method }\end{array}$} & \multirow[t]{2}{*}{ Ethnics } & \multirow{2}{*}{$\begin{array}{l}\text { HWE test } \\
p \text { value }\end{array}$} & \multirow[t]{2}{*}{ NOS } \\
\hline & & $\mathrm{GG}$ & GA & $\mathrm{AA}$ & GG & GA & AA & & & & & \\
\hline Jiang [14] & 2019 & 204 & 170 & 34 & 289 & 194 & 23 & IL-17A rs2275913 & PCR-RFLP & Asian & $Y(0.180)$ & 8 \\
\hline Han [15] & 2014 & 52 & 109 & 141 & 97 & 106 & 97 & IL-17A rs2275913 & PCR-SSCP & Asian & $N(0.000)$ & 7 \\
\hline Bai [16] & 2019 & 189 & 271 & 134 & 207 & 265 & 104 & IL-17A rs2275913 & PCR & Asian & $Y(0.235)$ & 7 \\
\hline Bafrani [18] & 2019 & 83 & 35 & 9 & 69 & 51 & 7 & IL-17A rs2275913 & PCR-RFLP & Caucasian & $Y(0.539)$ & 8 \\
\hline Vrgoc [17] & 2017 & 154 & 156 & 48 & 190 & 172 & 45 & IL-17A rs2275913 & $P C R$ & Caucasian & $Y(0.520)$ & 7 \\
\hline Eftedal [19] & 2019 & \multicolumn{3}{|c|}{$372 \mathrm{G}$ and $572 \mathrm{~A}$} & \multicolumn{3}{|c|}{ 396G and 638A } & IL-17A rs2275913 & $\mathrm{N} / \mathrm{A}$ & Caucasian & $\mathrm{N} / \mathrm{A}$ & 6 \\
\hline
\end{tabular}

$P$ value for Hardy-Weinberg equilibrium in the control groups. $N / A$, data not available, $Y$ yes, $N$ no, NOS Newcastle-Ottawa Quality Assessment Scale, $P C R-R F L P$ polymerase chain reaction and restriction fragment length polymorphism, SSCP single strand conformation polymorphism 
Table 2 Characteristics of the included studies of IL-17F(763780)

\begin{tabular}{|c|c|c|c|c|c|c|c|c|c|c|c|c|}
\hline \multirow[t]{2}{*}{ Authors } & \multirow[t]{2}{*}{ Years } & \multicolumn{3}{|l|}{ Case } & \multicolumn{3}{|c|}{ Control } & \multirow[t]{2}{*}{ Genotype } & \multirow{2}{*}{$\begin{array}{l}\text { Genotyping } \\
\text { method }\end{array}$} & \multirow[t]{2}{*}{ Ethnics } & \multirow{2}{*}{$\begin{array}{l}\text { HWE test } \\
p \text { value }\end{array}$} & \multirow[t]{2}{*}{ NO } \\
\hline & & $\pi$ & $\mathrm{TC}$ & $\mathrm{CC}$ & $\pi$ & TC & $\mathrm{CC}$ & & & & & \\
\hline Jiang [14] & 2019 & 356 & 49 & 4 & 423 & 80 & 2 & IL-17F rs763780 & PCR-RFLP & Asian & $Y(0.384)$ & 8 \\
\hline Han [15] & 2014 & 226 & 59 & 17 & 236 & 56 & 8 & IL-17F rs763780 & PCR-SSCP & Asian & $N(0.044)$ & 7 \\
\hline Bai [16] & 2019 & 380 & 188 & 26 & 411 & 155 & 10 & IL-17F rs763780 & $P C R$ & Asian & $Y(0.287)$ & 7 \\
\hline Bafrani [18] & 2019 & 98 & 26 & 3 & 112 & 13 & 2 & IL-17F rs763780 & PCR-RFLP & Caucasian & Y (0.091) & 8 \\
\hline Vrgoc [17] & 2017 & 393 & 48 & 1 & 493 & 34 & 1 & IL-17F rs763780 & PCR & Caucasian & $Y(0.610)$ & 7 \\
\hline Eftedal [19] & 2019 & \multicolumn{3}{|c|}{$905 \mathrm{~T}$ and $39 \mathrm{C}$} & \multicolumn{3}{|c|}{$1004 \mathrm{~T}$ and $30 \mathrm{C}$} & IL-17F rs763780 & $\mathrm{N} / \mathrm{A}$ & Caucasian & N/A & 6 \\
\hline
\end{tabular}

$P$ value for Hardy-Weinberg equilibrium in the control groups. $N / A$ data not available, $Y$ yes, $N$ no, NOS Newcastle-Ottawa Quality Assessment Scale, $P C R-R F L P$ polymerase chain reaction and restriction fragment length polymorphism, SSCP single strand conformation polymorphism

IL-17 gene polymorphisms and knee OA. Our metaanalysis involved a total of 2134 knee OA patients and 2306 controls (rs2275913) and 2134 knee OA patients and 2426 controls (rs763780). The distribution of genotypes of all the studies was tested with HWE and only 1 article [15] did not conform to it. Because genotype distribution data was not reported by Eftedal [19], only allele model was analyzed in the overall population and Caucasian population. More characteristics of the included articles are shown in Tables 1 and 2.

\section{Meta-analysis \\ Association between rs2275913 polymorphism and knee $O A$ susceptibility}

Based on the test results of heterogeneity, we used fixed effect model $\left(I^{2}<50 \%\right.$ and $\left.p>0.10\right)$ for recessive model and random effect model $\left(I^{2}>50 \%\right.$ and $\left.p<0.10\right)$ for allele model and dominant model to make this meta-analysis. The result of the association between IL-17A(rs2275913) gene polymorphisms and the risk of knee OA and the heterogeneity test are shown in Table 3. Our analysis suggested that allele A and genotype AA of the rs2275913 polymorphism were associated with high knee OA risk (allele model (A vs G) $\mathrm{OR}=$
$1.21,95 \%$ CI $1.01-1.45, p=0.040$, recessive model $(\mathrm{AA}$ vs $\mathrm{GG}+\mathrm{GA}) \mathrm{OR}=1.50,95 \%$ CI $1.25-1.79, p=$ 0.000 , Figs. 2, 3, and 4).

In order to reduce the heterogeneity of the analysis, we performed sub-group analyses to investigate the effect of the ethnicity with the risk of the knee OA. The results showed that there was a significant difference between the subgroups. In the Asian group, all the three models showed a great association between IL$17 \mathrm{~A}(\mathrm{rs} 2275913)$ gene polymorphisms and the risk of knee OA (dominant model: OR:1.50, 95\% CI 1.07-2.09, allele model: OR1.41, 95\% CI 1.10-1.80, recessive model: OR1.57, 95\% CI 1.28-1.92). Especially in recessive model, the heterogeneity was low $\left(I^{2}=26.3 \%, p=\right.$ 0.257), which makes the results more valuable. In the Caucasian group, however, the results suggested that the IL-17A(rs2275913) gene polymorphisms were not associated with knee OA risk in all genetic models (Table 3) and the heterogeneity was decreased significantly in recessive model $\left(I^{2}=0 \%, p=0.932\right)$ and allele model $\left(I^{2}=\right.$ $29.8 \%, p=0.240$ ).

Sensitivity analysis was also used to determine the pooled ORs regarding the effects of this SNP on knee OA risk by omitting each study in turn to determine the

Table 3 OR and 95\% Cl for OA and IL-17A rs2275913 under different genetic models

\begin{tabular}{|c|c|c|c|c|c|c|c|}
\hline \multirow[t]{2}{*}{ Genetic model } & \multirow[t]{2}{*}{ Ethnics } & \multirow[t]{2}{*}{ Studies } & \multicolumn{3}{|c|}{ Association test } & \multirow{2}{*}{$\begin{array}{l}\text { Heterogeneity } \\
p \text { value }\end{array}$} & \multirow{2}{*}{$\begin{array}{l}\text { Begg's } \\
\text { test } p \\
\text { value }\end{array}$} \\
\hline & & & OR & $95 \% \mathrm{Cl}$ & $p$ value & & \\
\hline \multirow{3}{*}{$\begin{array}{l}\text { Dominant model } \\
\text { (GA + AA vs GG) }\end{array}$} & Total & 5 & 1.25 & $0.93-1.67$ & 0.019 & 0.002 & \multirow[t]{3}{*}{0.806} \\
\hline & Asian & 3 & 1.50 & $1.07-2.09$ & 0.693 & 0.018 & \\
\hline & Caucasian & 2 & 0.89 & $0.49-1.61$ & 0.138 & 0.040 & \\
\hline \multirow[t]{3}{*}{ Allele model (A vs G) } & Total & 6 & 1.21 & $1.01-1.45$ & 0.040 & 0.001 & \multirow[t]{3}{*}{0.851} \\
\hline & Asian & 3 & 1.41 & $1.10-1.80$ & 0.006 & 0.011 & \\
\hline & Caucasian & 3 & 1.04 & $0.88-1.22$ & 0.658 & 0.240 & \\
\hline \multirow{3}{*}{$\begin{array}{l}\text { Recessive model } \\
\text { (AA vs GG + GA) }\end{array}$} & Total & 5 & 1.50 & $1.25-1.79$ & 0.000 & 0.452 & \multirow[t]{3}{*}{0.806} \\
\hline & Asian & 3 & 1.57 & $1.28-1.92$ & 0.000 & 0.257 & \\
\hline & Caucasian & 2 & 1.25 & $0.84-1.87$ & 0.265 & 0.932 & \\
\hline
\end{tabular}




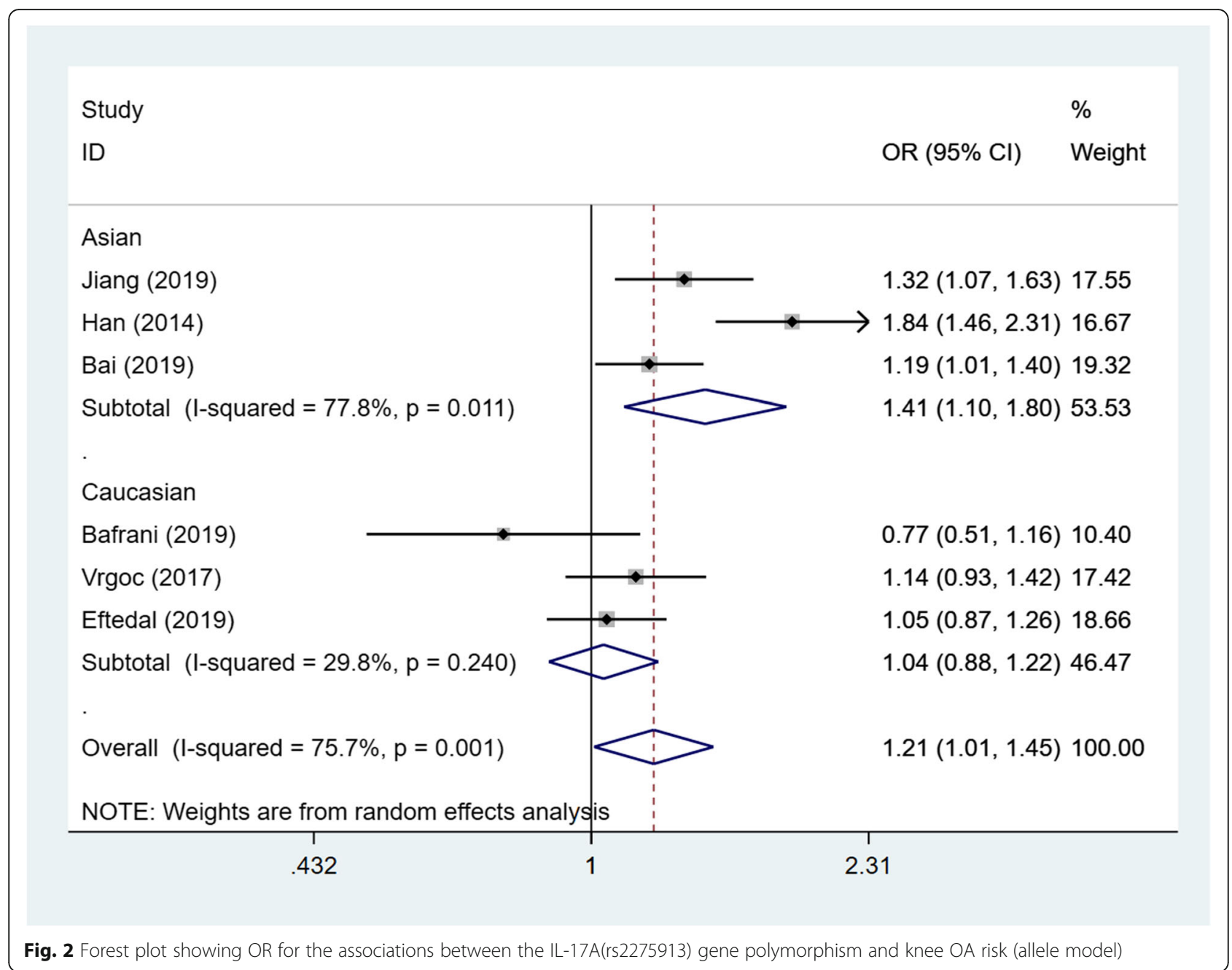

effect on the heterogeneity test and evaluate the stability of the overall results. Furthermore, one article in this study did not conform to HWE and the investigation was excluded in our sensitivity analysis. We found that the results in our sensitivity analysis were consistent with those in non-sensitivity analysis; the results indicated that our data were stable and credible.

\section{Association between rs763780 polymorphism and knee OA susceptibility}

Based on the test results of heterogeneity, we used fixed effect model $\left(I^{2}<50 \%\right.$ and $\left.p>0.10\right)$ for recessive model and random effect model $\left(I^{2}>50 \%\right.$ and $p$ $<0.10$ ) for allele model and dominant model to make this meta-analysis. The results of the association between IL-17F(rs763780) gene polymorphisms and the risk of knee OA and the heterogeneity test are shown in Table 4. Our analysis suggested that the $\mathrm{C}$ allele and genotype $\mathrm{CC}$ of the rs763780 polymorphism were associated with knee OA risk (allele model ( $\mathrm{C}$ vs $\mathrm{T}$ ) $\mathrm{OR}=1.35,95 \% \mathrm{CI} 1.08-1.68, p=0.008$, recessive model $(\mathrm{CC}$ vs TT $+\mathrm{TC}) \mathrm{OR}=2.28,95 \%$ CI $1.39-$ 3.76, $p=0.001$, Figs. 5, 6, and 7).

We then performed sub-group analyses to investigate the effect of the ethnicity with the risk of the knee OA. In the Asian group, recessive model showed a great association between IL-17F(rs763780) gene polymorphisms and the risk of knee OA (recessive model: OR 2.41, 95\% CI 1.42-4.10), and the heterogeneity was low $\left(I^{2}=0 \%, p=0.953\right)$ which makes the results more valuable. In the Caucasian group, the results suggested that the IL-17F(rs763780) gene polymorphisms were associated with knee OA risk in dominant model and allele model (dominant model: OR 1.88, 95\% CI 1.29-2.75; allele model: OR 1.66, 95\% CI 1.25-2.22, Table 4). The heterogeneity was decreased significantly in all three models $\left(I^{2}=0 \%, p>0.05\right)$ in the Caucasian group, we believe that ethnic was the main source of heterogeneity.

Sensitivity analysis was used to determine the pooled ORs regarding the effects of this SNP on knee OA risk by omitting each study in turn to determine the effect on the heterogeneity test. One study involved in our 


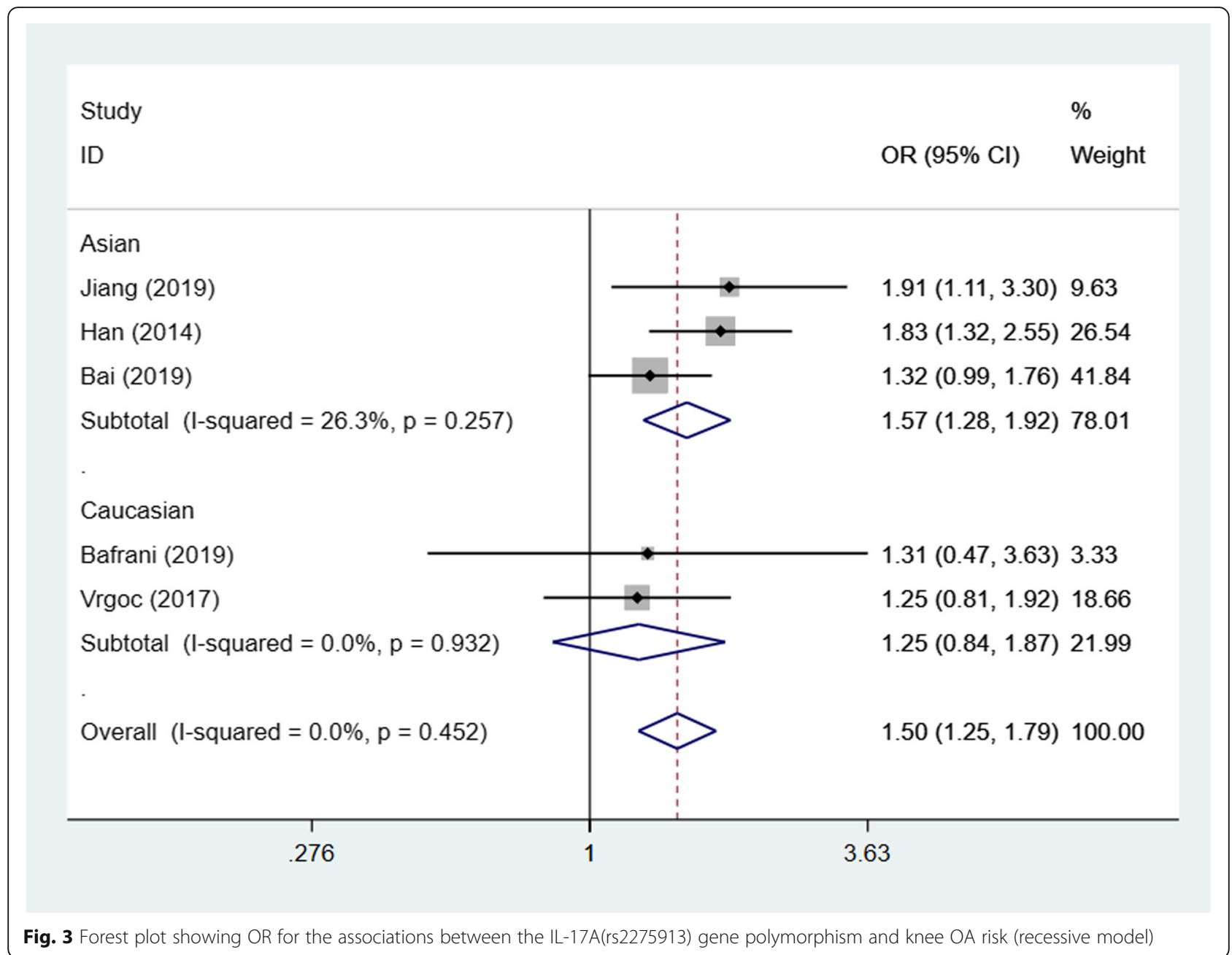

study did not conform to HWE and it was excluded in our sensitivity analysis. We found that the results in our sensitivity analysis were consistent with those in nonsensitivity analysis, the results indicated that our data were stable and credible.

\section{Publication bias analysis}

Begg's test were performed to quantitatively evaluate the publication bias of literatures on knee OA. The results of the Begg's test suggested that there was no evidence of publication bias in the meta-analyses of the association between the IL-17A(rs2275913) and IL$17 \mathrm{~F}(\mathrm{rs} 763780)$ gene polymorphisms and risk of knee OA $((p>0.05$, Tables 3 and 4$)$.

\section{Discussion}

To our knowledge, this is the first meta-analysis to investigate the associations between IL-17A(rs2275913) and IL-17F(rs763780) gene SNPs and knee OA risk. The most important finding was that polymorphisms of IL$17 \mathrm{~A}(\mathrm{rs} 2275913)$ and IL-17F(rs763780) gene associate with the risk of knee osteoarthritis in different ethnics. This finding proves our assumption that polymorphisms of IL-17A/F are associated with the occurrence of knee osteoarthritis and is a risk factor for the knee OA.

The definite mechanisms of the knee OA remain unknown, but many studies have shown that genetic factors are considered to be strong determinants with them, and the occurrence of knee osteoarthritis is related to inflammatory and cytokines [22-24]. Recent studies have suggested that knee OA might be considered a chronic inflammatory disorder, elevated levels of IL-1, IL-6, IL-17,TNF- $\alpha$, and other acute-phase proteins that are found in patients with cartilage degradation [25]. A kind of conventional viewpoint is that inflammatory mechanism plays a crucial role in the pathogenesis and evolution of cartilage degeneration and expression of inflammatory reaction [26-28]. IL-17 is one of the most important regulators of innate and adaptive immune responses, and it is expressed in synovial tissues, and could contribute to cartilage degeneration and synovial infiltration in joint by inducing the release of 


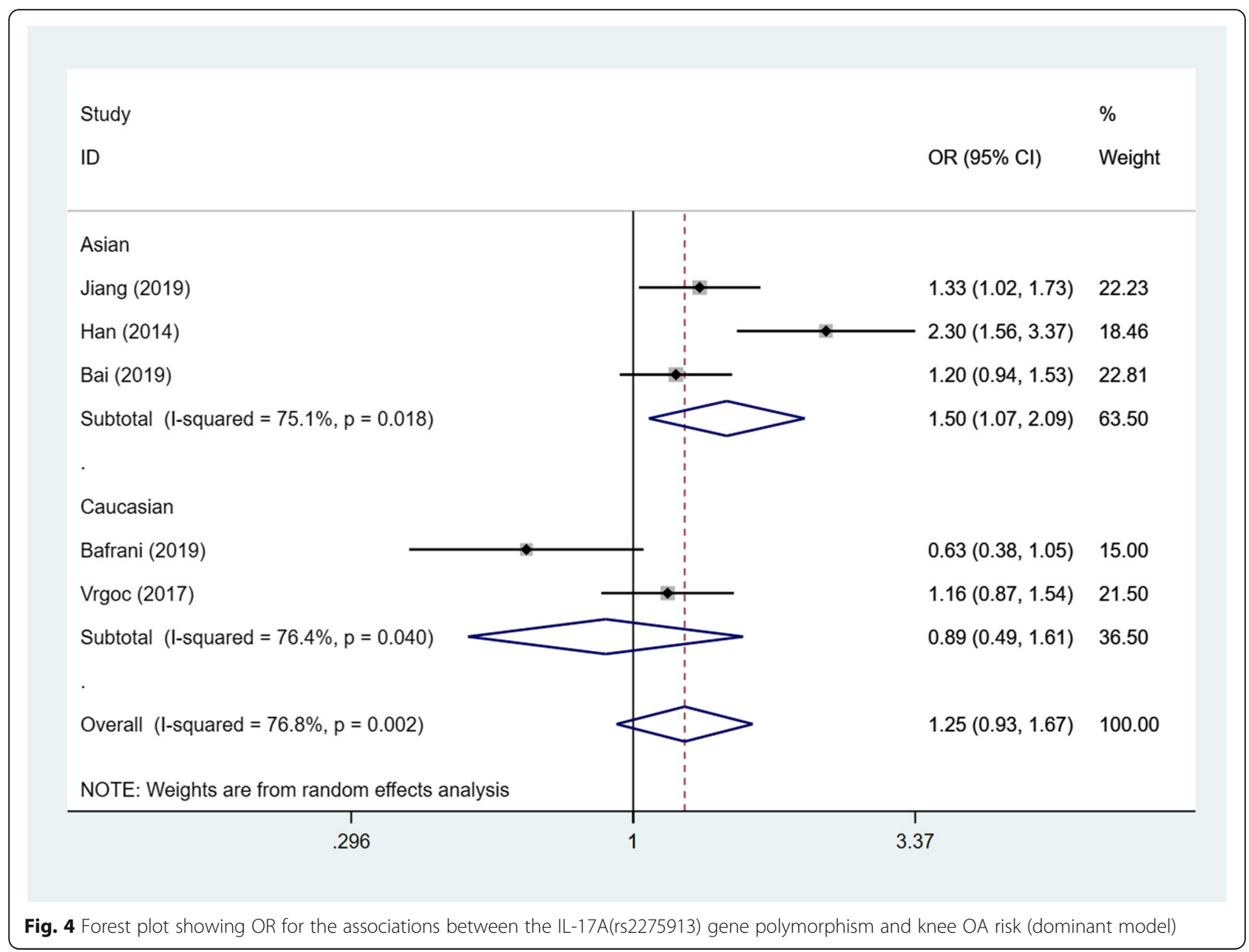

chemokines by chondrocytes $[29,30]$. Furthermore, studies in animal models suggest that IL-17 knock-out mice contribute to more severe RA than wild-type animals [31]. We have reasons to believe that IL-17 may contribute to the development of knee OA. Therefore, we conducted this meta-analysis to provide more confident evidence.
In our study, 6 eligible studies, including 2134 knee OA patients and 2306 controls for gene rs2275913 and 2134 knee OA patients and 2426 controls $\mathrm{s}$ for gene rs763780, were identified and analyzed. We demonstrated the association between IL-17A(rs2275913) and IL-17F(rs763780) and the knee OA risk by a metaanalysis to obtain a convincing conclusion. Our research

Table 4 OR and 95\% CI for OA and IL-17F rs763780 under different genetic models

\begin{tabular}{|c|c|c|c|c|c|c|c|}
\hline \multirow[t]{2}{*}{ Genetic model } & \multirow[t]{2}{*}{ Ethnics } & \multirow[t]{2}{*}{ Studies } & \multicolumn{3}{|c|}{ Association test } & \multirow{2}{*}{$\begin{array}{l}\text { Heterogeneity } \\
p \text { value }\end{array}$} & \multirow{2}{*}{$\begin{array}{l}\text { Begg's } \\
\text { test } p \\
\text { value }\end{array}$} \\
\hline & & & OR & $95 \% \mathrm{Cl}$ & $p$ value & & \\
\hline \multirow[t]{3}{*}{ Dominant model (TC + CC vs TT) } & Total & 5 & 1.32 & $0.97-1.80$ & 0.073 & 0.017 & 0.221 \\
\hline & Asian & 3 & 1.12 & $0.78-1.60$ & 0.533 & 0.029 & \\
\hline & Caucasian & 2 & 1.88 & $1.29-2.75$ & 0.001 & 0.582 & \\
\hline \multirow[t]{3}{*}{ Allele model (C vs T) } & Total & 6 & 1.35 & $1.08-1.68$ & 0.008 & 0.061 & 0.452 \\
\hline & Asian & 3 & 1.18 & $0.86-1.62$ & 0.302 & 0.032 & \\
\hline & Caucasian & 3 & 1.66 & $1.25-2.22$ & 0.001 & 0.703 & \\
\hline \multirow[t]{3}{*}{ Recessive model (CC vs $T+T C$ ) } & Total & 5 & 2.28 & $1.39-3.76$ & 0.001 & 0.953 & 0.086 \\
\hline & Asian & 3 & 2.41 & $1.42-4.10$ & 0.001 & 0.889 & \\
\hline & Caucasian & 2 & 1.41 & $0.31-3.76$ & 0.655 & 0.969 & \\
\hline
\end{tabular}




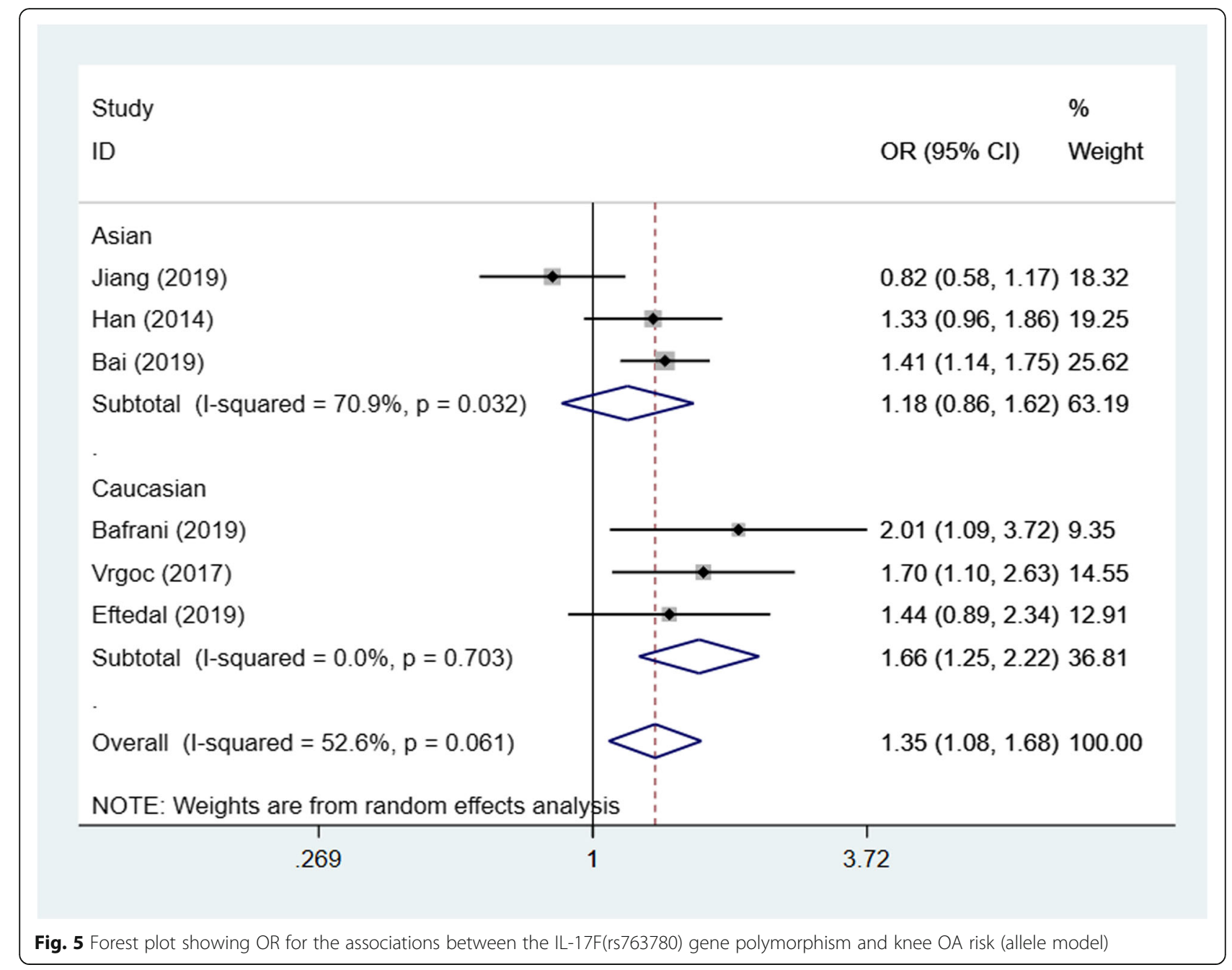

suggests that IL-17A(rs2275913) and IL-17F(rs763780) gene polymorphisms are a risk factor for knee osteoarthritis $(p<0.05)$. Different alleles play different roles in the occurrence of knee OA. As for IL-17A(rs2275913), it is believed that allele $\mathrm{A}$ can promote the high expression of IL-17A, which may be a risk factor for the occurrence of osteoarthritis. In our study, the A allele in case groups was indeed higher than that in the control groups. And we found the OR was higher than 1 in allele model and recessive model, which means A allele can be a mutant gene influence the development of knee OA. The genotype of IL-17F(rs763780) was similar to IL-17 $\mathrm{A}(\mathrm{rs} 2275913)$. The OR of allele model $(\mathrm{C}$ vs $\mathrm{T})$ and recessive model $(\mathrm{CC}$ vs TT $+\mathrm{TC})$ was higher than 1 , while the OR with $95 \%$ CI of dominant model (TC + CC vs TT) was $0.97-1.80$. This means CC genotype can increase the risk of knee $\mathrm{OA}$, and we can conclude that the $\mathrm{C}$ allele was a mutant gene and recessively expressed in human.

Subgroup analysis revealed that the results were altered between Asian and Caucasian groups. The heterogeneity was decreased significantly in recessive model $\left(I^{2}=0 \%, p=0.932\right)$ and allele model $\left(I^{2}=29.8 \%\right.$, $p=0.240)$ of IL-17A(rs2275913) and all three models $\left(I^{2}\right.$ $=0 \%, p>0.05)$ of IL-17 A(rs2275913) in the Caucasian group, we believe that ethnic was the main source of heterogeneity. Heterogeneity mainly exists in the Asian group, which may be related to the complex ethnic composition of the Asian population. Subgroup analysis stratified by ethnicity demonstrated that A allele increased the risk of knee OA in Asian. While in Caucasian, no association was found between IL-17 $\mathrm{A}(\mathrm{rs} 2275913)$ and the risk of knee OA. The results seem intriguing that there is an association in the overall population but without positive result in subgroups. It could be probably statistically insufficient when the majority of cases of the study were originated from Asian. And one other possibility may relate to the different expression patterns of IL-17A and IL-17F in nonhomogeneous ethnic populations.

Despite the fact that the result shows a relevance between IL-17A(rs2275913) and IL-17F(rs763780) and risk 


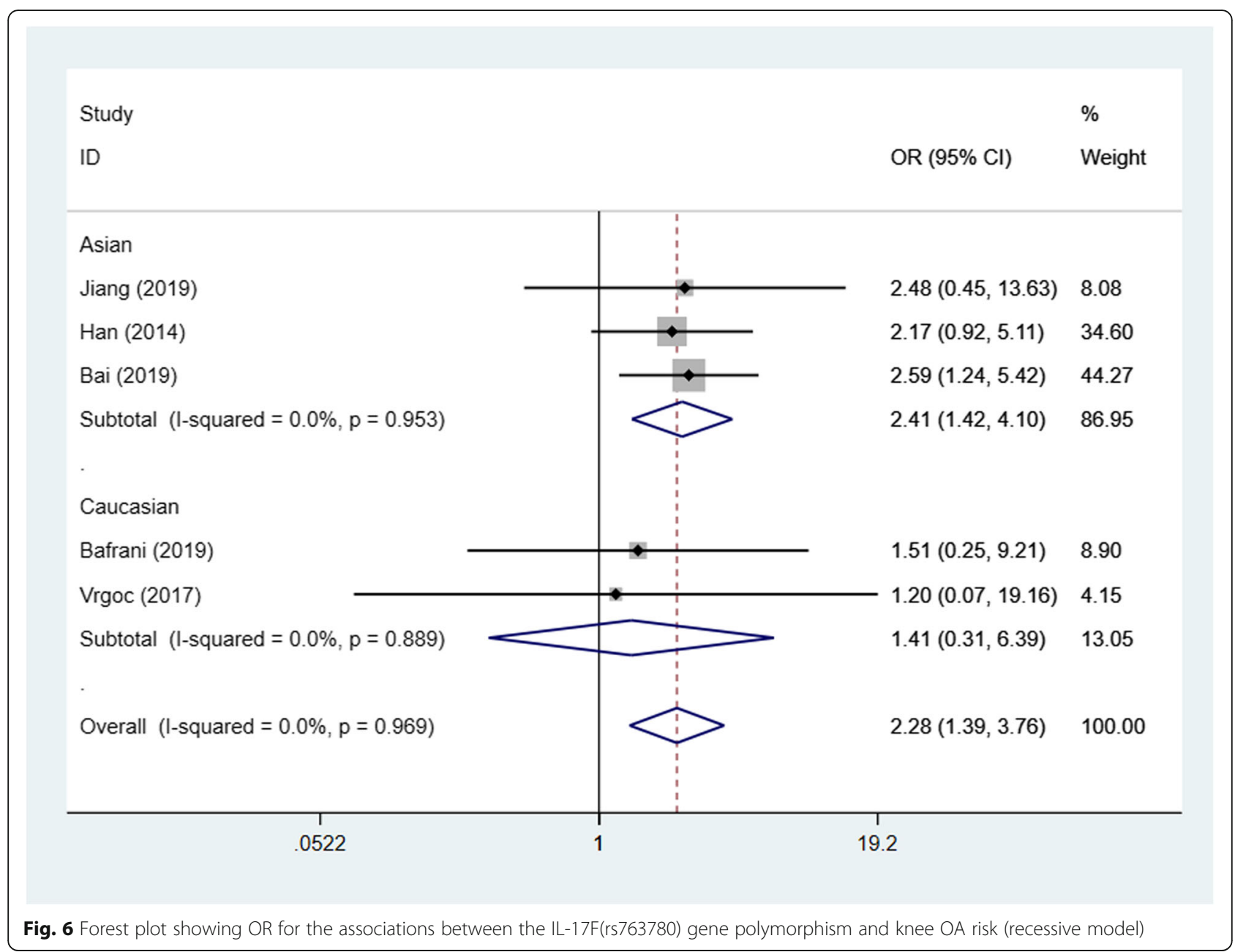

of knee OA, there are still some facts we cannot ignore. Firstly, the occurrence of knee osteoarthritis is a comprehensive result of a variety of factors and genes, and a single gene may have little impact on this result. Secondly, there may be some unidentified alleles affecting the expression of IL-17, and the gene loci (rs2275913, rs763780) may not be the only factor affecting the expression of IL-17 in the population. Third, regardless of the fact that IL-17A and IL-17F can mediate cartilage degeneration, it may not be a direct determinant of osteoarthritis. Many cytokines of IL-17 family are involved in the inflammatory reaction. The destruction of articular cartilage is the common result of many cytokines. IL-17 cannot directly reflect the effect of inflammatory reaction changes on osteoarthritis. Subgroup analysis in our study shows no statistical difference in different ethnic groups; gene expression may still have a certain influence, in spite of considering the limited articles involved.

There are still some limitations in our paper. Firstly, our several genetic models have great heterogeneity when combining OR values, which may affect the accuracy of the article. For this reason, we used random effect model to combine OR values and conduct subgroup analysis to reduce the impact of heterogeneity. In this way, results of heterogeneity test are acceptable in some subgroups. Secondly, although six papers have been included in the study, the data scale is still small, and further experiments with larger samples in different ethnic populations are needed to verify this conclusion. Thirdly, since the data is not completely available, the potential confounding factors (such as age, gender) were not adjusted in this study. Last, though there was no obvious publication bias revealed by Begg's test, the selection bias could not be completely removed because only studies published in English were included.

\section{Conclusion}

In conclusion, this meta-analysis revealed an association between the polymorphism of IL-17A(rs2275913) gene and high risk of knee OA only in Asians. By contrast, the IL-17F(rs763780) gene polymorphisms may increase 


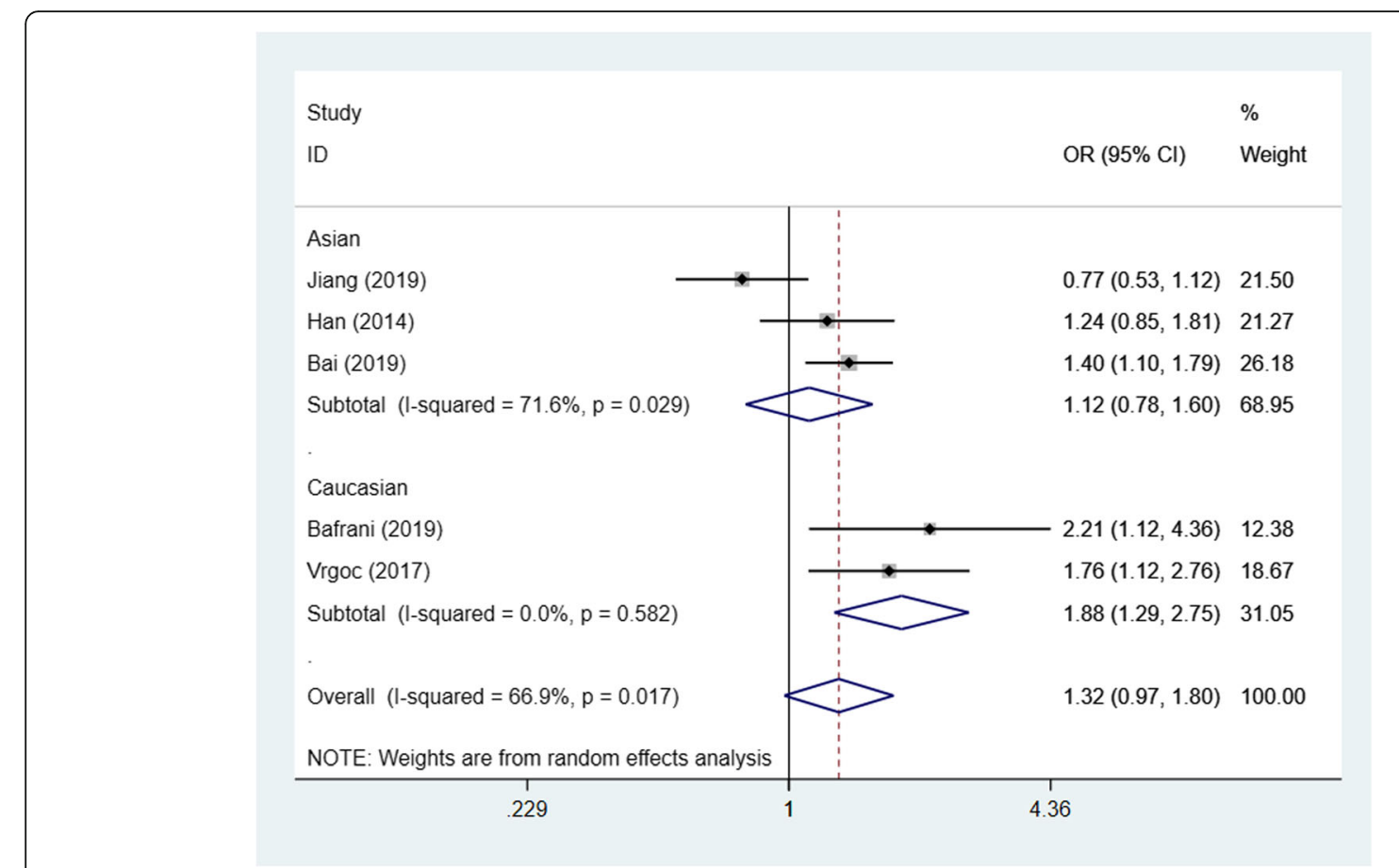

Fig. 7 Forest plot showing OR for the associations between the IL-17F(rs763780) gene polymorphism and knee OA risk (dominant model)

the risk of knee OA both in Asians and Caucasians. However, because of the limitations of the sample size, further studies with larger samples in different ethnic populations could be performed to verify this conclusion.

\section{Supplementary information}

Supplementary information accompanies this paper at https://doi.org/10. 1186/s13018-019-1495-0.

Additional file 1: PRISMA 2009 Checklist.

\section{Abbreviations}

IL: Interleukin; Cls: Confidence intervals; OR: Odds ratio; OA: Osteoarthritis; SNPs: Single nucleotide polymorphisms; HWE: Hardy Weinberg equilibrium

\section{Acknowledgements}

Not applicable.

\section{Authors' contributions}

FF-L and QD-Z contributed to the conception and design. WS-G and QD-Z did the interpretation. P-L and FFL did the data collection and analysis. FF- $L$ wrote the article. QD-Z and WG-W did the final approval of the version to be submitted.

\section{Funding}

This study was funded by National Natural Science Foundation of China (grant number 81703896, 81673776), Beijing municipal science and technology commission (grant number Z171100001017209), and the Capital Health Research and Development of Special (grant number 2016-2-4062).

The Fund's role is to provide review and publishing costs.

\section{Availability of data and materials}

Not applicable.
Ethics approval and consent to participate

All procedures performed in studies involving human participants were in accordance with the ethical standards of the institutional and/or national research committee and with the 1964 Helsinki declaration and its later amendments or comparable ethical standards.

\section{Consent for publication}

Not applicable.

\section{Competing interests}

The authors declare that they have no competing interests.

\section{Author details}

${ }^{1}$ China-Japan Friendship School of Clinical Medicine, Peking University, No.2 Yinghua East Street, Beijing 100029, China. ${ }^{2}$ Beijing University of Chinese Medicine, Yinghua East Street, Beijing 100029, China. ${ }^{3}$ Department of Orthopedic Surgery, Beijing Key Lab Immune-Mediated Inflammatory Diseases, China-Japan Friendship Hospital, No.2 Yinghua East Street, Beijing ,100029, China.

Received: 5 July 2019 Accepted: 27 November 2019

Published online: 16 December 2019

\section{References}

1. Brandt KD, Dieppe P, Radin EL. Etiopathogenesis of osteoarthritis. Rheum Dis Clin North Am. 2008;34:531-59.

2. Deshpande BR, Katz JN, Solomon DH, Yelin EH, Hunter DJ, Messier SP, Suter LG, Losina E. Number of persons with symptomatic knee osteoarthritis in the US: impact of race and ethnicity, age, sex, and obesity. Arthritis Care Res (Hoboken). 2016;68:1743-50

3. Michou L. Genetics of digital osteoarthritis. JOINT BONE SPINE. 2011;78:347-51.

4. Kan J, Mishima S, Kashiwakura J, Sasaki-Sakamoto T, Seki M, Saito S, Ra C, Tokuhashi Y, Okayama Y. Interleukin-17A expression in human synovial mast cells in rheumatoid arthritis and osteoarthritis. Allergol Int. 2016;65(Suppl): S11-6.

5. Askari A, Naghizadeh MM, Homayounfar R, Shahi A, Afsarian MH, Paknahad A, Kennedy D, Ataollahi MR. Increased Serum Levels of IL-17A and IL-23 are 
associated with decreased vitamin D3 and increased pain in osteoarthritis. Plos One. 2016;11:e0164757.

6. Wang Z, Zheng C, Zhong Y, He J, Cao X, Xia H, Ba H, Li P, Wu S, Peng C. Interleukin-17 can induce osteoarthritis in rabbit knee joints similar to hulth's method. Biomed Res Int. 2017;2017:2091325.

7. Wan L, Zhao Q, Niu G, Xiang T, Ding C, Wang S. Plasma miR-136 can be used to screen patients with knee osteoarthritis from healthy controls by targeting IL-17. EXP THER MED. 2018;16:3419-24.

8. van Baarsen LG, Lebre MC, van der Coelen D, Aarrass S, Tang MW Ramwadhdoebe TH, Gerlag DM, Tak PP. Heterogeneous expression pattern of interleukin 17A (IL-17A), IL-17F and their receptors in synovium of rheumatoid arthritis, psoriatic arthritis and osteoarthritis: possible explanation for nonresponse to anti-lL-17 therapy? Arthritis Res Ther. 2014; 16:426.

9. Skalska U, Kontny E. Adipose-derived mesenchymal stem cells from infrapatellar fat pad of patients with rheumatoid arthritis and osteoarthritis have comparable immunomodulatory properties. Autoimmunity. 2016;49: $124-31$

10. Rana A, Minz RW, Aggarwal R, Anand S, Pasricha N, Singh S. Gene expression of cytokines (TNF-alpha, IFN-gamma), serum profiles of IL-17 and IL-23 in paediatric systemic lupus erythematosus. Lupus. 2012;21:1105-12.

11. Attur MG, Patel RN, Abramson SB, Amin AR. Interleukin-17 up-regulation of nitric oxide production in human osteoarthritis cartilage. Arthritis Rheum. 1997:40:1050-3

12. de Lange-Brokaar BJ, loan-Facsinay A, van Osch GJ, Zuurmond AM, Schoones J, Toes RE, Huizinga TW, Kloppenburg M. Synovial inflammation, immune cells and their cytokines in osteoarthritis: a review. Osteoarthritis Cartilage. 2012;20:1484-99.

13. Southam L, Heath O, Chapman K, Loughlin J. Association analysis of the interleukin 17 genes IL17A and IL17F as potential osteoarthritis susceptibility loci. Ann Rheum Dis. 2006;65:556-7.

14. Jiang L, Zhou X, Xiong Y, Bao J, Xu K, Wu L. Association between interleukin-17A/F single nucleotide polymorphisms and susceptibility to osteoarthritis in a Chinese population. Medicine. 2019;98:e14944.

15. Han L, Lee HS, Yoon JH, Choi WS, Park YG, Nam SW, Lee JY, Park WS. Association of IL-17A and IL-17F single nucleotide polymorphisms with susceptibility to osteoarthritis in a Korean population. GENE. 2014;533:119-22.

16. Bai Y, Gao S, Liu Y, Jin S, Zhang H, Su K. Correlation between Interleukin-17 gene polymorphism and osteoarthritis susceptibility in Han Chinese population. Bmc Med Genet. 2019;20(1):20.

17. Vrgoc G, Vrbanec J, Eftedal RK, Dembic PL, Balen S, Dembic Z, Jotanovic Z. Interleukin-17 and Toll-like Receptor 10 genetic polymorphisms and susceptibility to large joint osteoarthritis. J Orthop Res ${ }^{\bullet}$. 2018;36:1684-93.

18. Bafrani $\mathrm{HH}$, Ahmadi M, Jahantigh D, Karimian M. Association analysis of the common varieties of IL17A and IL 17F genes with the risk of knee osteoarthritis. J Cell Biochem. 2019;120(10):18020-30.

19. Eftedal R, Vrgoc G, Jotanovic Z, Dembic Z. Alternative interleukin 17A/F locus haplotypes are associated with increased risk to hip and knee osteoarthritis. J Orthop Res. 2019;37(9):1972-8.

20. MANTEL N, HAENSZEL W. Statistical aspects of the analysis of data from retrospective studies of disease. J Natl Cancer Inst. 1959;22:719-48.

21. DerSimonian R, Laird N. Meta-analysis in clinical trials revisited. Contemp Clin Trials. 2015;45:139-45.

22. Favero M, Belluzzi E, Trisolino G, Goldring MB, Goldring SR, Cigolotti A, Pozzuoli A, Ruggieri P, Ramonda R, Grigolo B, Punzi L, Olivotto E. Inflammatory molecules produced by meniscus and synovium in early and end-stage osteoarthritis: a coculture study. J CELL PHYSIOL. 2019;234:11176-87.

23. Zhang C, Zhang Z, Chang Z, Mao G, Hu S, Zeng A, Fu M. miR-193b-5p regulates chondrocytes metabolism by directly targeting histone deacetylase 7 in interleukin-1 beta-induced osteoarthritis. J Cell Biochem. 2019.

24. Machado C, Resende GG, Macedo R, Do NV, Branco AS, Kakehasi AM, Andrade MV. Fibroblast-like synoviocytes from fluid and synovial membrane from primary osteoarthritis demonstrate similar production of interleukin 6, and metalloproteinases 1 and 3. Clin Exp Rheumatol. 2019;37:306-9.

25. Fernandes JC, Martel-Pelletier J, Pelletier JP. The role of cytokines in osteoarthritis pathophysiology. Biorheology. 2002;39:237-46.

26. Robert M, Miossec P. IL-17 in Rheumatoid arthritis and precision medicine: from synovitis expression to circulating bioactive levels. Front Med (Lausanne). 2018;5:364.

27. Park JS, Choi SY, Hwang SH, Kim SM, Choi J, Jung KA, Kwon JY, Kong YY, Cho ML, Park SH. CR6-interacting factor 1 controls autoimmune arthritis by regulation of signal transducer and activator of transcription 3 pathway and Thelper type 17 cells. Immunology. 2019;156:413-21.

28. Rosser EC, Lom H, Bending D, Duurland CL, Bajaj-Elliott M, Wedderburn LR. Innate lymphoid cells and T cells contribute to the interleukin-17A signature detected in the synovial fluid of patients with juvenile idiopathic arthritis. Arthritis Rheumatol. 2019;71:460-7.

29. Kolls JK, Linden A. Interleukin-17 family members and inflammation. IMMUNITY. 2004;21:467-76.

30. Jin W, Dong C. IL-17 cytokines in immunity and inflammation. Emerg Microbes Infect. 2013;2:e60.

31. Jin Y, Chen X, Gao Z, Liu K, Hou Y, Zheng J. Expression levels of IL-15 and IL-17 in synovial fluid of rheumatoid arthritis animal model. Exp Ther Med. 2018;16:3377-82.

\section{Publisher's Note}

Springer Nature remains neutral with regard to jurisdictional claims in published maps and institutional affiliations.

\section{Ready to submit your research? Choose BMC and benefit from:}

- fast, convenient online submission

- thorough peer review by experienced researchers in your field

- rapid publication on acceptance

- support for research data, including large and complex data types

- gold Open Access which fosters wider collaboration and increased citations

- maximum visibility for your research: over $100 \mathrm{M}$ website views per year

At BMC, research is always in progress.

Learn more biomedcentral.com/submissions 